\title{
PROPOSIÇÃO E APLICAÇÃO DE UM MODELO DE DIAGNÓSTICO ORGANIZACIONAL: UM ESTUDO DE CASO
}

\author{
Adriano Wagner ${ }^{1}$ \\ Eugenio Andrés Díaz Merino ${ }^{2}$
}

\begin{abstract}
Resumo: $O$ objetivo deste artigo é a proposição de um modelo de diagnóstico organizacional que exponha um panorama sistêmico e consistente de informações acerca da performance das empresas. A partir de princípios da pesquisa exploratória e procedimentos de pesquisa bibliográfica, foram reunidos subsídios de periódicos científicos e literatura especializada, que embasaram a formatação de um modelo constituído por quatro fases: (1) caracterização do sistema de valor; (2) composição de indicadores de desempenho; (3) aferição do desempenho; $e$ (4) análise de performance. A aplicação prática do modelo permitiu compreender relações da empresa com o ambiente competitivo e condições da sua estrutura gerencial e operacional. Este panorama foi concretizado por meio da descrição da Cadeia de Valor, da definição de indicadores de desempenho, da aferição das medidas parametrizadas em cada indicador e dos mapas cromáticos de análise, que expõem a performance da organização. Este estudo contribui com inovações no processo de diagnóstico organizacional, fortalecendo a gestão estratégica das organizações.
\end{abstract}

Palavras chave: Diagnóstico Organizacional; Gestão Estratégica; Modelo; Processo.

\section{PROPOSITION AND APPLICATION OF AN ORGANIZATIONAL DIAGNOSIS MODEL: A CASE STUDY}

\begin{abstract}
The objective of this article is the proposition of an organizational model diagnosis that exposes a systematic and consistent panorama of information about the performance of companies. From the principles of the exploratory research and bibliographic research procedures, were gathered contributions from scientific journals and specialized literature, that supported the formatting of a four-phase model: (1) characterization of the value system; (2) composition of performance indicators; (3) performance measurement; and (4) performance analysis. The practical application of the model allowed the understanding of the relations of the company with its competitive environment and the conditions of its managerial and operational structure. This scenario was achieved through the description of the Value Chain, the definition of performance indicators, the measurement of the parameterized measurements in each indicator and the color analysis maps, which present the performance of the organization. This study contributes with innovations in the process of organizational diagnosis, consolidating the strategic management of organizations.
\end{abstract}

Keywords: Organizational Diagnosis; Strategic management; Model; Process.

\section{PROPOSICIÓN Y APLICACIÓN DE UN MODELO DE DIAGNÓSTICO ORGANIZACIONAL: UN ESTUDIO DE CASO}

\begin{abstract}
Resumen: El objetivo de este artículo es una propuesta de un modelo de diagnóstico organizaconal que exponga un panorama sistémico y consistente de informaciones acerca del desempeño de las empresas. Com base en los principios de la investigación exploratoria y los procedimientos de investigación bibliográfica, se agruparse subsidios de revistas científicas y literatura técnica, que respaldaron el formateo de un modelo que consta de cuatro fases: (1) la caracterización del sistema de valores; (2) composición de los indicadores de desempeño; (3) evaluación del desempeño; y (4) análisis de desempeño. La aplicación práctica del modelo permitió compreender las relaciones de la empresa con el entorno competitivo y las condiciones de su estructura gerencial y operativa. Este escenario se logró mediante la descripción de la cadena de valor, la definición de indicadores de desempeño, la medición de las medidas parametrizadas en cada indicador y los mapas de análisis de color, que exponen el desempeño de la organización. Este estudio contribuye a las innovaciones en el proceso de diagnóstico organizacional, fortaleciendo la gestión estratégica de las organizaciones.
\end{abstract}

Palabras Clave: Diagnóstico Organizacional; Gestión estratégica; Modelo; Proceso.

\footnotetext{
${ }^{1}$ Professor e pesquisador no Instituto Federal de Educação, Ciência e Tecnologia Farroupilha, IFrar - Campus Santa Rosa. Doutor em Engenharia da Produção pela Universidade Federal de Santa Catarina.

2 Doutorado em Engenharia de Produção pela Universidade Federal de Santa Catarina, Brasil (2000) Professor Titular da Universidade Federal de Santa Catarina.
} 


\section{Introdução}

Diversos aspectos da conjuntura político-econômica, das inovações tecnológicas e das forças competitivas de mercado exercem influência no desempenho das organizações. A dinâmica destes elementos intervém na gestão e estabelece condições que afetam a performance dos negócios. Requerem atenção para que sejam analisados e considerados nas atividades gerenciais e no desenvolvimento da eficiência operacional e eficácia mercadológica.

Há o desafio do permanente monitoramento da conjuntura organizacional. Para tal, são necessários processos eficientes de coleta de dados e análise de informações que demonstrem as condições do desempenho econômico, mercadológico, gerencial e operacional. O processo de diagnóstico organizacional se apresenta como um dos quesitos importantes do trabalho de gerenciamento e condução dos negócios. As decisões nos diferentes níveis da hierarquia requerem domínio e conhecimento sobre atividades, recursos disponíveis e ambiente institucional e operacional das empresas. São tomadas com base em análises de informações sobre mercados, clientes e consumidores, tecnologias do próprio setor e de outros e considerando o contexto das finanças e aspectos da economia (PRICE e NEWSON, 2003; BARNEY e HESTERLY, 2010).

Por isso, resultam evidências de que o desenvolvimento do diagnóstico organizacional possibilita a geração de um mapa analítico sobre a conjuntura organizacional e qualifica o processo de tomada de decisão entre os gestores. Esta condição é possível mediante um processo de diagnóstico realizado por meio de modelos que reúnem métodos e ferramentas para exploração e análise de dados e informações acerca das organizações e suas relações com o ambiente externo.

Assim, a questão norteadora do estudo foi: quais aperfeiçoamentos no processo de diagnóstico organizacional podem qualificar as informações que subsidiam o processo decisório? Diante da problemática exposta, o objetivo deste artigo é apresentar os resultados da aplicação prática de um modelo sugerido de diagnóstico organizacional, por meio de estudo de caso realizado em uma organização industrial fabricante de móveis.

A importância de estudos sobre o tema deriva de trabalhos de autores que posicionam o processo de diagnóstico organizacional como elemento central na gestão e desenvolvimento de bons níveis na performance das organizações. Processos conduzidos com minúcia reúnem dados e informações que promovem conclusões precisas sobre intervenções e mudanças necessárias (PORTER, 1979, 1983, 1985a, 2008; MOUTINHO, RITA e LI, 2006; SAEED e WANG, 2013).

O modelo de diagnóstico organizacional aplicado incorpora inovações/ferramentas no levantamento de informações e análise do desempenho organizacional. Instrumentaliza a definição de indicadores de desempenho por meio do levantamento de requisitos para obtenção 
de desempenho superior. Propõe a aferição das medidas parametrizadas em cada indicador via um sistema de comparação entre valores aferidos e métricas de desempenho estabelecidas para cada aspecto sob avaliação. Encerra-se gerando mapas cromáticos que expõem a performance da organização, com base na relação entre o grau de desempenho e o potencial de melhoria dos itens.

O estudo de caso foi realizado no setor moveleiro, especificamente em uma empresa fabricante de móveis localizada no estado do Rio Grande do Sul, no extremo sul do Brasil. Nesta região, o segmento moveleiro possui relevância em virtude da representatividade que a indústria possui. Segundo dados do Instituto de Estudos e Marketing Industrial (IEMI, 2015) e da Associação Brasileira das Indústrias do Mobiliário (ABIMÓVEL, 2015), a região é a quarta maior em número de indústrias moveleiras, com 13,5\% do total nacional, perfazendo 2,7 mil companhias que empregam mais de 48 mil pessoas e geram $\mathrm{R} \$ 8,2$ bilhões em valor de produção.

\section{Metodologia}

Este artigo descreve os resultados de um trabalho realizado em três etapas: (1) formação da base teórica sobre o tema de pesquisa; (2) desenvolvimento e proposição do modelo; e (3) aplicação prática do modelo proposto por meio de estudo de caso. O desenvolvimento geral das três etapas da pesquisa seguiu o delineamento exposto no Quadro 1.

Quadro 1 - Planejamento da pesquisa

\begin{tabular}{|c|c|}
\hline Tarefa & Delineamento \\
\hline Delimitação do tema de pesquisa & Processo de diagnóstico organizacional. \\
\hline Pressuposto & $\begin{array}{c}\text { O diagnóstico organizacional possibilita a geração de um mapa analítico } \\
\text { sobre a conjuntura organizacional e qualifica o processo de tomada de } \\
\text { decisão entre os gestores, principalmente se for realizado por meio de } \\
\text { modelos que reúnem métodos e ferramentas para exploração e análise } \\
\text { dos dados e informações acerca da realidade das organizações e suas } \\
\text { relações com o ambiente externo. }\end{array}$ \\
\hline Definição do objetivo da pesquisa & $\begin{array}{c}\text { Apresentar os resultados da aplicação prática de um modelo sugerido de } \\
\text { diagnóstico organizacional, por meio de estudo de caso realizado em } \\
\text { uma organização industrial fabricante de móveis. }\end{array}$ \\
\hline $\begin{array}{l}\text { Delineamento da metodologia da } \\
\text { pesquisa }\end{array}$ & $\begin{array}{c}\text { Etapa 1: base teórica. } \\
\text { Etapa 2: proposição do modelo. } \\
\text { Etapa 3: aplicação prática. } \\
\text { Classificação: Pesquisa básica estratégica; Pesquisa exploratória; } \\
\text { Pesquisa bibliográfica; e Estudo de caso. }\end{array}$ \\
\hline Estudo do estado da arte & $\begin{array}{l}\text { Levantamento e exploração de materiais bibliográficos convergentes } \\
\text { com o tema, problema e objetivo do trabalho. }\end{array}$ \\
\hline $\begin{array}{l}\text { Descrição do objeto do estudo: } \\
\text { modelo de diagnóstico organizacional }\end{array}$ & $\begin{array}{l}\text { Apresentação das referências, estrutura e dinâmica do modelo de } \\
\text { processo de diagnóstico organizacional. }\end{array}$ \\
\hline Apresentação do caso aplicado & $\begin{array}{c}\text { Descrição da utilização prática do modelo de processo de diagnóstico } \\
\text { organizacional na organização industrial do setor moveleiro. }\end{array}$ \\
\hline Encaminhamentos finais & Considerações finais sobre a proposta apresentada no estudo realizado. \\
\hline
\end{tabular}

Fonte: Dados da pesquisa (2019) 
No âmbito geral, quanto a finalidade, este trabalho se classifica como pesquisa básica estratégica (GIL, 2010), pois está voltado ao desenvolvimento de conhecimentos direcionados à amplas áreas, visando a solução de reconhecidos problemas práticos. Neste estudo, esta condição encontra-se na realização de diagnóstico organizacional, um processo inserto nos pressupostos da gestão estratégica, imbuído da geração sistêmica de informações sobre o conjunto de aspectos que estão entre as fronteiras dos ambientes interno e externo às organizações.

No que tange ao desenvolvimento de cada etapa específica da pesquisa, foram requeridos procedimentos metodológicos que fundamentassem o planejamento e realização do trabalho. No Quadro 2 são ilustrados os procedimentos metodológicos relativos a cada etapa.

Quadro 2 - Procedimentos metodológicos

\begin{tabular}{|c|c|c|}
\hline Etapa & Aspectos Metodológicos & Instrumentos/Técnicas \\
\hline $\begin{array}{c}\text { Etapa 1: Formação da } \\
\text { Base Teórica }\end{array}$ & $\begin{array}{c}\text { Pesquisa Bibliográfica e } \\
\text { Pesquisa Exploratória. }\end{array}$ & Livros e Artigos; Bases de dados; e Mendeley. \\
\hline $\begin{array}{c}\text { Etapa 2: Proposição do } \\
\text { Modelo }\end{array}$ & Pesquisa Exploratória. & $\begin{array}{c}\text { Análise exploratória; e Reunião de materiais com } \\
\text { temas convergentes. }\end{array}$ \\
\hline $\begin{array}{c}\text { Etapa 3: Aplicação } \\
\text { Prática }\end{array}$ & $\begin{array}{c}\text { Pesquisa Básica Estratégica } \\
\text { e Estudo de Caso. }\end{array}$ & $\begin{array}{c}\text { Observação sistemática; Entrevistas; Questionários; } \\
\text { Análise descritiva; e Planilhas de cálculo. }\end{array}$ \\
\hline
\end{tabular}

Fonte: Dados da pesquisa (2019)

Em relação ao desenvolvimento da pesquisa, a etapa (1) foi realizada por meio de pesquisa exploratória e pelas diretrizes da pesquisa bibliográfica. A pesquisa exploratória tem como finalidade proporcionar um conjunto de informações sobre o assunto investigado (PRODANOV e FREITAS, 2013). A pesquisa bibliográfica permite a sistematização de informações que possibilitam a formação de referências e conhecimentos acercado dos temas em pauta.

Os materiais compilados e utilizados foram extraídos em livros e em artigos pesquisados em bases de dados científicos, as quais são: Computers \& Applied Sciences Comlplete (EBSCO), Emerald, Engeneering Village (compendex), Scielo, Science Direct, Scopus e Web of Science. Os nexos de busca foram os termos "organizational diagnostic/diagnosis", "organizational analysis", "enterprise analysis". A seleção inicial seguiu as leis de Bradford, Lotka e Zipf que norteiam a pesquisa bibliométrica (GUEDES e BORSCHIVER, 2005; ZUPIC e CATER, 2014), a qual ocorreu a partir da análise dos títulos e palavras-chave e a leitura e análise dos resumos e introduções dos materiais. Após a triagem preliminar, ocorreu o estudo pormenorizado dos textos reunidos. Para a compilação e organização dos materiais, utilizou-se o sistema livre de gerenciamento e compartilhamento de documentos de pesquisa Mendeley Desktop, versão 1.16.3. 
O exame dos materiais reunidos na etapa (1) formou subsídios e referências que permitiram arquitetar a estrutura, definir o escopo, descrever as premissas e estabelecer a dinâmica de um modelo de diagnóstico organizacional, conforme previsto na etapa (2) do trabalho. A aplicação prática do modelo proposto (etapa 3) foi realizada por meio de estudo de caso, em que a pesquisa ocorre em um profundo estudo que permite amplo e detalhado conhecimento da realidade investigada (YIN, 2001; GIL, 2010; COOPER e SCHINDLER, 2016).

A empresa participante foi fundada no ano de 1987 e é de característica familiar. Possui aproximadamente 40 funcionários e o faturamento gira em torno de $\mathrm{R} \$ 1$ milhão mensais. Está localizada na cidade de Bento Gonçalves, região serrana do estado do Rio Grande do Sul/Brasil. O foco do negócio é o desenvolvimento, fabricação e comercialização de mobiliário para escritórios (home e office) e móveis escolares/educacionais. O mix de produtos é de aproximadamente 370 itens em linha.

Para o levantamento das informações necessárias para a realização do estudo, foram utilizadas as estratégias de observação sistemática e de questionários, durante o primeiro semestre de 2016. O processo foi coordenado e conduzido por uma equipe de oito colaboradores, formado pelas direções e representantes das áreas comercial, industrial e administrativa, denominado grupo gestor. $\mathrm{O}$ tratamento dos dados foi realizado com o auxílio das planilhas de cálculo do aplicativo Excel, produto da Microsoft Office 365, em virtude de oferecem ambiente favorável para tabulação dos dados, realização dos cálculos estatísticos e geração de gráficos de análise.

\section{Diagnóstico Organizacional}

De acordo com Sacomano Neto e Truzzi (2002), o diagnóstico organizacional tem origem nos primórdios dos estudos e práticas sobre gestão. Consiste em decisões e ações que permitam assegurar que as empresas formulem e mantenham adaptações benéficas com o seu ambiente (WRIGHT, KROLL e PARNELL, 1998; NAG, HAMBRICK e CHEN, 2007).

A sistemática da gestão estratégica, proposta por Barney e Hesterly (2010), projeta um conjunto inicial de decisões para estabelecer missão e objetivos, que são referências norteadoras sobre o futuro desejado, como demonstra a Figura 1. Após, um coeso processo de diagnóstico deve ser conduzido, no sentido de identificar e analisar os aspectos internos e externos que influenciam no desempenho das empresas. A partir das referências, inovações ou adaptações nas estratégias e operações são decididas e implantadas, com prognóstico de obtenção de vantagens competitivas. 
Figura 1 - Processo de gestão estratégica

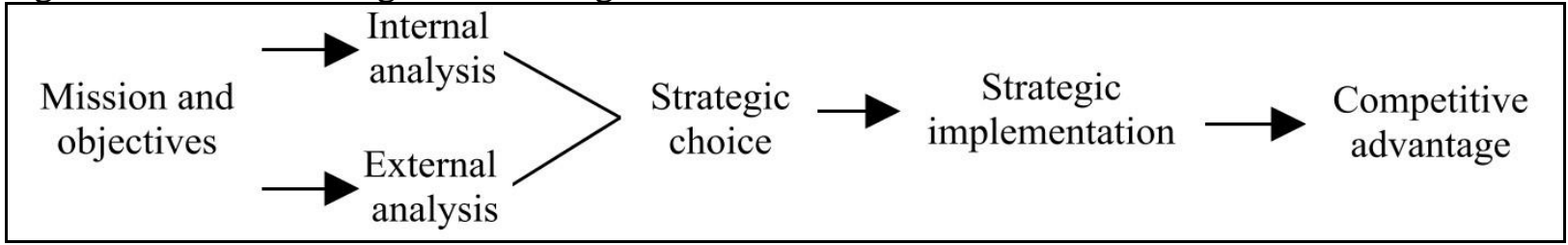

Fonte: Adaptado de Barney e Hesterly (2010)

Bissell e Keim (2008) argumentam que os modelos de avaliação organizacional geralmente se concentram sobre a eficácia das organizações, principalmente no que tange aos termos financeiros. No entanto, enfatizam que os modelos de diagnóstico devem ver a organização como um sistema de partes que interagem, pois as intervenções são facilitadas na medida em que os atores compartilham informações e experiências.

A realização do diagnóstico aufere melhores resultados se forem utilizados modelos no desdobramento dos processos envolvidos. Saeed e Wang (2013), defendem que os modelos devem ser baseados nos seguintes critérios: A natureza do modelo de diagnóstico deve ser compreensível e não excessivamente complexa; O modelo de diagnóstico deve ser adequado à organização sob avaliação e ser abrangente, mas simples o suficiente para cobrir questões centrais de análise; e $\mathrm{O}$ modelo deve primar pela coleta, compilação e exposição de dados durante o diagnóstico.

Em vista disso, o diagnóstico organizacional se constitui num dos elementos essenciais no contexto da gestão estratégica. Enseja o emprego de técnicas e esforços para o trabalho de exploração e formatação de informações, de modo a elaborar um panorama sobre aspectos positivos e oportunidades, bem como das fragilidades e dos desafios a serem enfrentados. Possibilita a análise e compreensão do ambiente organizacional via um processo interpretativo, a partir do quadro informacional construído, o que possibilita a geração de prognósticos com embasamento técnico e a tomada de decisão gerencias com eficiência e sustentação.

\section{Proposição de um Modelo para o Processo de Diagnóstico Organizacional}

O modelo de diagnóstico organizacional doravante descrito possibilita a identificação, a sistematização e a avaliação das condições de aspectos que influenciam o desempenho organizacional, sejam eles do âmbito interno, relativo aos recursos e capacidades empresariais, ou externos, voltados aos aspectos macro ambientais e competitivos. Organizado em quatro fases, como mostra a Figura 2, prescreve metodologicamente o processo de levantamento de dados, a geração de informações, a aferição dos níveis de desempenho e a análise da performance do conjunto de aspectos avaliados, em consonância com os pressupostos de Bissell 
e Keim (2008), que teorizam o diagnóstico como a avaliação aprofundada do sistema organizacional.

Figura 2 - Estrutura geral do modelo de processo de diagnóstico organizacional

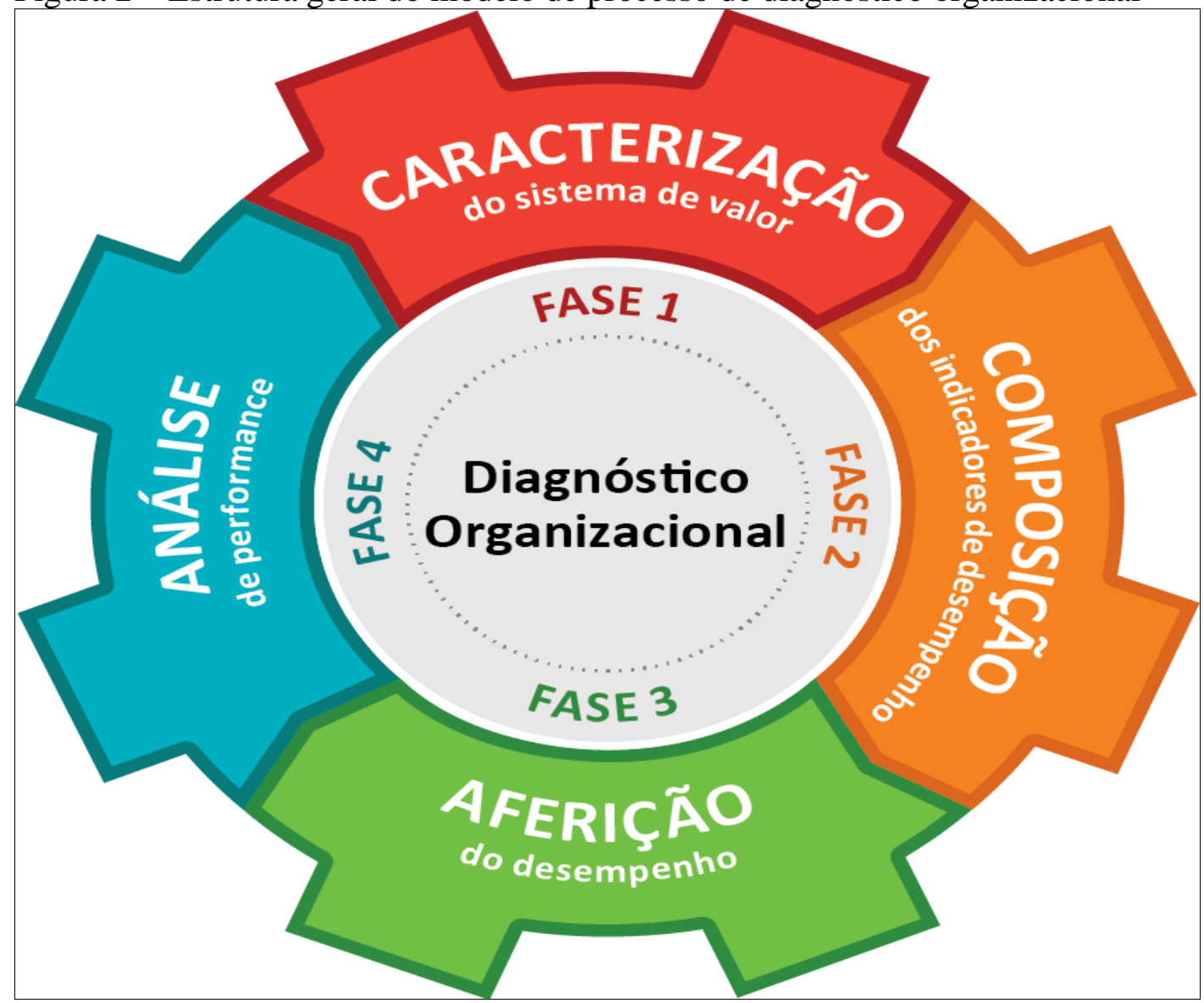

Fonte: Dados da pesquisa (2019)

O desdobramento de cada parte subsidia as atividades da etapa seguinte, cada qual agregando novos componentes que formalizam um compêndio sistêmico-avaliativo sobre os fenômenos sob exame. O escopo do processo de diagnóstico organizacional proposto reside em:

a) Procedimentar o mapeamento/caracterização do contexto atual da empresa e suas relações com o ambiente externo;

b) Aferir dos níveis de desempenho por meio de indicadores e métricas de análise;

c) Analisar a performance organizacional pela relação entre o grau de desempenho e o potencial de melhoria que os aspectos avaliados possuem, pois mudanças planejadas e implementadas tendem a alterar o comportamento da performance nas futuras avaliações.

A representação do modelo em formato circular permite visualizar o processo de diagnóstico como uma engrenagem dentro de um sistema maior. A força recebida impulsiona o movimento do conjunto em fluxos cíclicos. Naves et al. (2000) argumentam que em razão da complexidade da organização e do processo de interpretação da conjuntura e funcionamento, não 
é possível analisar as situações e o contexto organizacional como processos lineares, mas sim como eventos circulares. O ciclo avaliativo seguinte absorverá o resultado das modificações realizadas, apontando para o êxito, neutralidade ou malogro das decisões e ações realizadas.

A compreensão sistêmica inclui a prerrogativa de construir-se um diagnóstico a partir da percepção dos atores partícipes da conjuntura sob diagnose. Estes atores estão situados em áreas e setores diferentes, exercendo funções específicas e com níveis de autoridade distintos, no entanto, sob a égide das regras da organização. Engendra-se um panorama que permita a geração de feedbacks que alimentem os pontos favoráveis e/ou provocam decisões e ações para modificar-se ou proteger-se das condições desfavoráveis (O’CONNOR e McDERMOTT, 1997).

\subsection{Fase 1: Caracterização do Sistema de Valor}

A primeira fase tem como objetivo compreender o contexto empresarial e os aspectos que influenciam na competitividade das organizações. $O$ desdobramento desta fase é operacionalizado por meio do mapeamento da Cadeia de Valor, seguindo os preceitos de Porter (1985a, 1985b, 1991, 2008). A Cadeia de Valor permite desagregar a empresa nas suas atividades relevantes para compreender os custos e as fontes existentes e potenciais de diferenciação (Porter, 1985b).

Defende-se a necessidade de distinguir-se e compreender-se as forças subjacentes que influenciam na competitividade e lucratividade do setor de atuação. As bases de referência em relação a cadeia e sistema de valor estão na obra de Porter $(1979 ; 1980 ; 1983 ; 1985 b ; 1991$; 2008). Os estudos de Ramos-Rodríguez e Ruíz-Navarro (2004) e Nerur, Rasheed e Natarajan (2008) apontam Porter como o mais influente autor neste campo de estudos.

\subsection{Fase 2: Composição dos Indicadores de Desempenho}

A segunda fase tem por finalidade a definição de um conjunto de indicadores que possibilite a aferição do desempenho da empresa. As questões que orientam esta fase do processo são: o que interfere e determina o desempenho da organização e quais indicadores utilizar para avaliar o Grau de Desempenho? As respostas à estas indagações procuram identificar elementos que possibilitem avaliar o desempenho de aspectos externos que exercem influência na estrutura e atuação da empresa e fatores internos que determinam sua performance operacional.

$\mathrm{Na}$ distinção destes elementos, compreende-se que a identificação de Requisitos de Desempenho Superior (RDS’s) possibilita apontar itens que suportem aferição quantitativa e que revelem com objetividade a atual conjuntura dos fenômenos sob análise no processo de diagnóstico organizacional. Os requisitos são condições e exigências necessárias para que se 
concretize algo ou se atinja necessidades e expectativas e para a solução de problemas ou atingimento de objetivos estabelecidos. Se relacionam aos aspectos humanos e materiais que afetam o desempenho (INTERNATIONAL INSTITUTE OF BUSINESS ANALYSIS, 2009).

A definição dos RDS's é de competência dos stakeholders que possuem vínculo direto nos processos gerenciais e operacionais e as melhores condições de compreensão de questões relativas a Cadeia de Valor e forças competitivas que versam sobre a estratégia, estrutura, organização dos recursos, capacidades e competências frente ao cenário competitivo (GREGORY et al., 2007).

\subsection{Fase 3: Aferição do Desempenho}

A aferição tem por finalidade mensurar as condições de desempenho da organização, com base nos aspectos que foram levantados e os indicadores definidos na Fase 2. Para isso, presumese que a ferramenta proposta por Merino, Gontijo e Merino (2012), denominada de Modelo CDS (Competitividade - Diferenciação - Sustentabilidade), que absorve os pressupostos da exploração e análise preconizados no Design (LOVE, 2000), possibilita gerar um extrato de parâmetros que permitem a avaliação quantitativa e qualitativa do desempenho, conforme indicadores da fase 2.

Anterior a efetiva aferição do desempenho, o modelo prescreve que para cada indicador sejam definidas métricas. Na sequência, são realizadas as medições pelos indicadores estabelecidos, as quais podem ocorrer de múltiplas maneiras, de acordo com o objetivo, o fator e a medida de cada indicador. Lok e Crawford (2000) expõem que uma das ferramentas eficazes para a compreensão das questões organizacionais e a condução do seu desenvolvimento são os questionários, em virtude de promoverem ofeedback dos aspectos sob avaliação.

Todavia, o grau de desempenho é aferido por meio da equiparação do resultado que cada indicador logrou e as métricas estabelecidas, utilizando, para tanto, a escala Likert, numa variança entre 1 e 5, apenas com números inteiros. Na escala, o valor (1) corresponde a um impacto negativo, o valor (3) é considerado neutro e o valor (5) indica uma potencialidade. Os números (2 e 4) são intermediários. Para facilitar a visualização quanto ao valor atribuído ao indicador ou dimensão, uma escala de cor gradual é relacionada aos valores, conforme demostrado na Figura 3, que também apresenta o diagrama do modelo. 

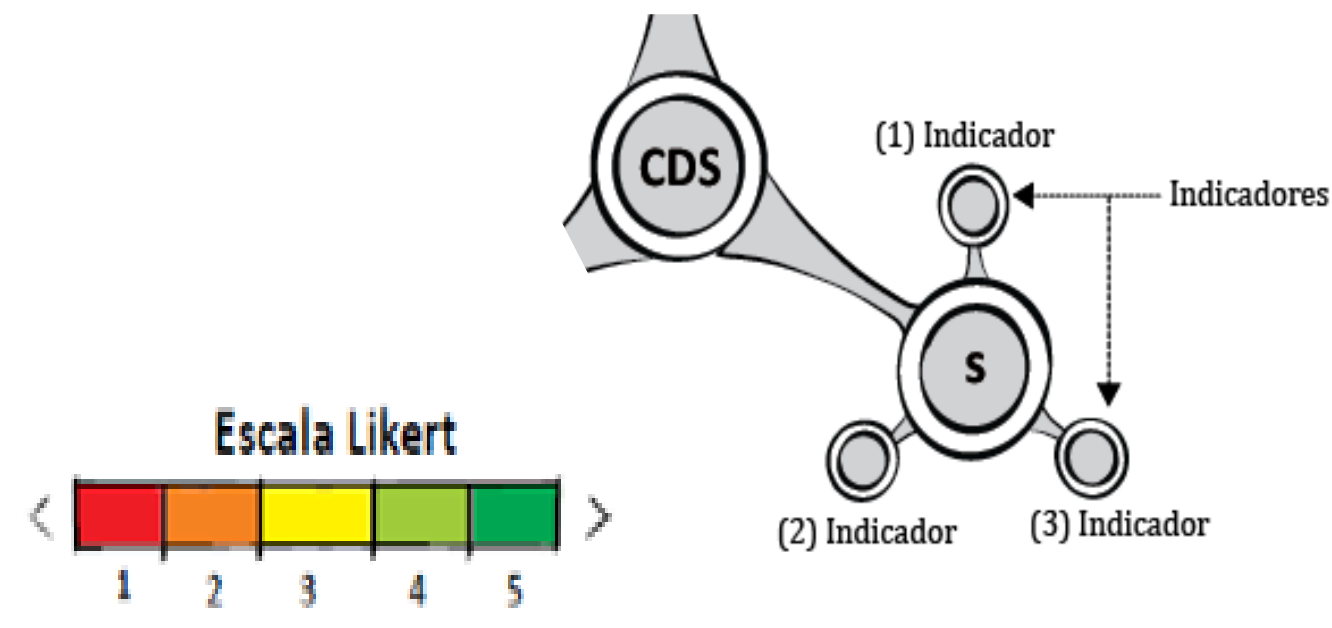

(2) Indicador

(3) Indicador

Fonte: Adaptado de Merino, Gontijo e Merino (2012)

A combinação dos elementos visuais (dimensões, indicadores e cores) mostra-se importante no modelo CDS, por possibilitar um processo mais rápido e coeso de tomadas de decisões, em processo de diagnóstico. Os pressupostos para aplicação do modelo estão referenciados nos estudos de Merino, Gontijo e Merino (2012), Piazza, Teixeira e Merino (2012), Garcia (2013) e Merino, Merino e Wagner (2017).

\subsection{Fase 4: Análise de Performance}

A última fase do modelo de diagnóstico sistematiza o arcabouço de informações que expressa o desempenho da organização, agregado de um parecer sobre o potencial futuro que cada aspecto sob avaliação apresenta. Utiliza-se aqui o termo Performance para justificar a grandeza que esta fase possui, em função de indicar a relação entre o grau de desempenho aferido pelos indicadores e o potencial de melhoria que cada aspecto avaliado possui.

Esta análise é possibilitada pela geração de Mapas Cromáticos de Análise. A plotagem destes mapas é realizada tomando por base a construção de um gráfico de dispersão, baseado nestas variáveis: Grau de Desempenho e Nível Potencial de Melhoria. Este formato de análise é utilizado na matriz GE-McKinsey Nine-Box Matrix. A matriz foi desenvolvida para uma abordagem sistemática de tomada de decisão sobre investimentos (MCKINSEY e COMPANY, 2008).

A associação da matriz é estabelecida, tanto no eixo horizontal quanto vertical, na seguinte escala: alta; média; e baixa. O prognóstico das decisões é estabelecido de acordo com as características que cada área da matriz reporta. Neste mapa cromático, a análise da performance é favorecida pela utilização da escala cromática: Verde escuro - Verde claro - Amarelo - 
Laranja - Vermelho, conforme expõe a Figura 4. Cada cor representa um setor do mapa, que indica as características do aspecto aferido, assim como apresenta o Quadro 3.

Figura 4 - Mapa Cromático de Análise

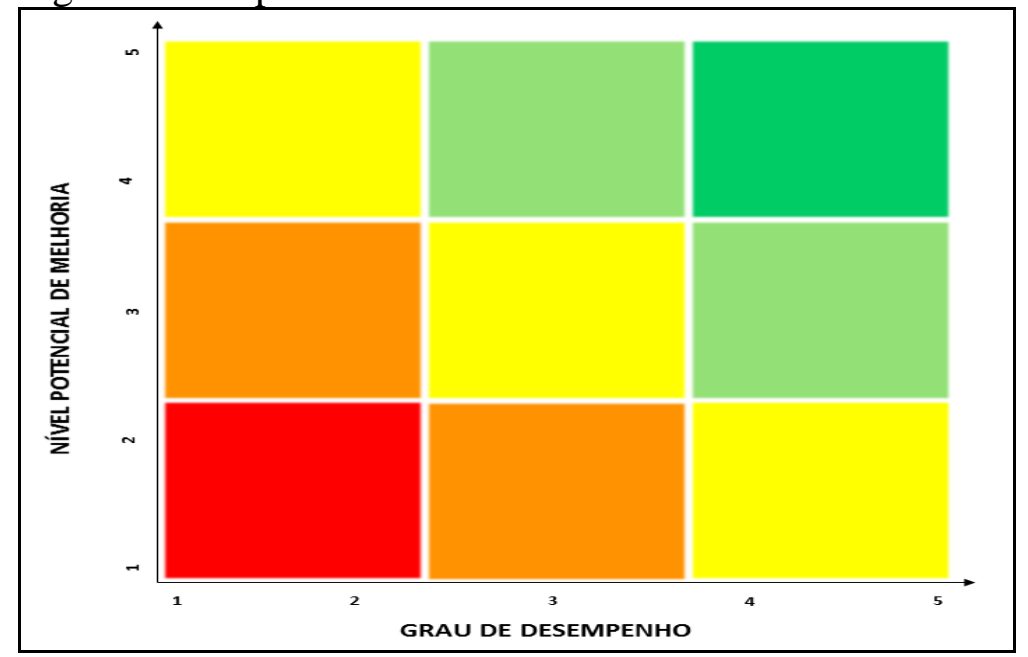

Fonte: Adaptado de McKinsey e Company (2008) e Jurevicius (2014)

Quadro 3 - Características por área

\begin{tabular}{|c|c|c|c|}
\hline Área & GD & NPM & Interpretação \\
\hline & Alto & Alto & $\begin{array}{c}\text { Concentra resultados Positivos no GD e condição de Alto NPM, no qual eficiência pode } \\
\text { ser explorada para melhoria do desempenho global da empresa. }\end{array}$ \\
\hline & Médio & Alto & $\begin{array}{l}\text { Concentra resultados Medianos no GD, mas que possuem condição de Alto NPM. A } \\
\text { eficiência não compromete o desempenho global da empresa, mas pode ser aperfeiçoado. }\end{array}$ \\
\hline & Alto & Médio & $\begin{array}{l}\text { Concentra resultados Positivos no GD, mas que possuem condição Média de NPM. A } \\
\text { eficiência é destaque e pode apresentar oportunidades para melhoria do desempenho } \\
\text { global da empresa. }\end{array}$ \\
\hline & Baixo & Alto & $\begin{array}{l}\text { Concentra resultados Ruins no GD, mas condição Alta de NPM, o que representa } \\
\text { possibilidades eminentes de avanço e contribuição para desempenho global da empresa. }\end{array}$ \\
\hline & Médio & Médio & $\begin{array}{l}\text { Concentra resultados Médios no GD e na condição do NPM. A definição de projetos e } \\
\text { ações deve priorizar a melhoria da eficiência, pois aprimorar os resultados pode } \\
\text { contribuir para o fortalecimento do desempenho global da empresa. }\end{array}$ \\
\hline & Alto & Baixo & $\begin{array}{c}\text { Concentra resultado Positivo no GD, mas a condição do NPM é Baixa. Aspectos nesta } \\
\text { área contribuem bem para o resultado global da empresa, mesmo sem perspectiva de } \\
\text { maior potencial. }\end{array}$ \\
\hline & Baixo & Médio & $\begin{array}{c}\text { Concentra resultados Ruins no GD e condição Média no NPM. Deve ser prioridade a } \\
\text { definição e implantação de projetos/ações para melhoria da eficiência, para não ocorrer } \\
\text { influência no desempenho global da empresa. }\end{array}$ \\
\hline & Médio & Baixo & $\begin{array}{c}\text { Concentra resultados Médios no GD e Baixa condição no NPM. É salutar definir e } \\
\text { implantar projetos e ações para a melhoria da eficiência para melhor contribuição com o } \\
\text { desempenho global da empresa. }\end{array}$ \\
\hline & Baixo & Baixo & $\begin{array}{c}\text { Concentra resultados Ruins e cujo prognóstico é de Baixo NPM, o que carece de Projetos } \\
\text { e Ações urgentes, pois pode comprometer o desempenho global da empresa. }\end{array}$ \\
\hline
\end{tabular}

Fonte: Dados da pesquisa (2019)

A realização do diagnóstico pela processualidade do modelo sugerido possui potencial de entregar aos gestores informações apontadas com rigor e critérios metódicos. Cumpridas as quatro fases, um conjunto sistêmico de informações e prognósticos estará à disposição dos stakeholders. Cada fase produz um compêndio de informações que subsidia a fase seguinte. No 
entanto, os dados gerados em cada fase, por si só permitem a percepção das condições do objeto que está sob diagnóstico. Esta característica retrata a importância do processo em detrimento do resultado final, em consequência do envolvimento com a realidade, por meio do uso de ferramentas e métodos que garantem rigor ao processo. No Quadro 4 estão resumidas as características e a entrega de cada fase do modelo de diagnóstico organizacional proposto.

Quadro 4-Atividades e entregas por fase do modelo

\begin{tabular}{|c|l|}
\hline Fase & \multicolumn{1}{|c|}{ Atividades } \\
\hline 1 & Descrição da Cadeia de Valor; e Identificação das Forças Competitivas. \\
\hline 2 & $\begin{array}{l}\text { Especificação de Requisitos de Desempenho Superior (RDS’s); e Definição de Indicadores de } \\
\text { Desempenho. }\end{array}$ \\
\hline 3 & Fixação de métricas para avaliação de desempenho; e Aferição do Grau de Desempenho (GD). \\
\hline 4 & $\begin{array}{l}\text { Estabelecimento dos Níveis Potenciais de Melhoria (NPM’s) para cada indicador; e Geração dos Mapas } \\
\text { Cromáticos para análise da performance. }\end{array}$ \\
\hline
\end{tabular}

Fonte: Dados da pesquisa (2019)

Os resultados do uso do modelo fortaleçam os princípios que fundamentam o processo de diagnóstico organizacional, considerando que as informações sobre as condições competitivas e operacionais das organizações são recursos estratégicos na tomada de decisão e que os processos de exploração, sistematização, visualização e intepretação rápida e sistêmica das informações são capacidades diferenciadas que influenciam na competitividade e diferenciação das organizações.

\section{Aplicação do Modelo Proposto: um Estudo de Caso}

\subsection{Desenvolvimento da Fase 1 - Caracterização do Sistema de Valor}

Esta fase possibilita a visualização e o conhecimento do contexto organizacional e de negócios e a identificação de aspectos que implicam nas condições competitivas da organização.

a) Especificação do contexto organizacional:

A especificação do contexto organizacional foi realizada via descrição da Cadeia de Valor da empresa. O mapeamento permitiu a compreensão ampla e acurada da constituição dos processos primários, dos processos de apoio e do valor gerado e fornecido ao mercado comprador.

No sistema geral de valor, a empresa tem posição intermediária, exercendo papel de transformadora ao adicionar valor aos insumos fornecidos pela cadeia a montante de sua posição, e fornecer itens manufaturados para canais de distribuição a jusante que fazem o relacionamento com o consumidor final. Os processos primários e os processos de apoio estão bem estabelecidos e as delimitações e responsabilidades são nítidas. A estrutura enxuta, com cadeia de comando e controle objetiva, favorece o gerenciamento. A Figura 5 apresenta a Cadeia de Valor. 
Figura 5 - Cadeia de Valor

\begin{tabular}{|c|c|c|c|c|c|c|c|}
\hline Planejamento & \multicolumn{5}{|c|}{ Planejamento Estratégico - Planejamento Financeiro -Planejamento Industrial -Planejamento Comercial } & & \\
\hline$P \& D$ & \multicolumn{5}{|c|}{ Pesquisa de Produtos-Pesquisa de Tendências-Pesquisa de Materiais-Design } & - Conhecimento; & \\
\hline Gerenciamento & \multicolumn{5}{|c|}{ Processos Administrativos -Contabilidade-Saúde e Segurança do Trabalho - Alinhamento das área Comercial e Industrial } & - Funcionalidade; & \\
\hline Assessorias & \multicolumn{5}{|c|}{ Jurídica-Contábil -Tecnologia da Informação -Gestão Ambiental -Gestão de Custos-Energia Elétrica } & - Soluções; & $\bar{F}$ \\
\hline Tecnologias & \multicolumn{5}{|c|}{$\begin{array}{l}\text { Tecnologia em Processos Administrativos - Tecnologia dos Processos de Produção - Tecnologiade informaçãoe } \\
\text { Comunicação }\end{array}$} & $\begin{array}{l}\text { - Flexibilidade; } \\
\text { - Diferenciaçãa }\end{array}$ & \\
\hline Gestão de RH & \multicolumn{5}{|c|}{$\begin{array}{l}\text { Recrutamento-Seleção-Treinamento-Atividades de Departamento de Pessoal -Gestão do Relacionamento-Ações } \\
\text { Sociais }\end{array}$} & & \\
\hline Manutenção & \multicolumn{5}{|c|}{ Equipamentos TI-Máquinase Equipamentos-Sistema Elétrico-Predial-Veicular } & Cliente FINAL ${ }^{(\mathrm{a})}$ & \\
\hline Comercial & $\begin{array}{l}\text { Suprimentose } \\
\text { Almoxarifado }\end{array}$ & $\begin{array}{c}\text { Engenharia e } \\
\text { PCP }\end{array}$ & Metalurgia & Marcenaria & Expedição & Cliente CANAL ${ }^{(b)}$ & \\
\hline $\begin{array}{l}\text { - Prospecção e } \\
\text { captaçãode } \\
\text { clientes; } \\
\text { - Prospecção e } \\
\text { captaçãode } \\
\text { representantes; } \\
\text { - Relacionamento } \\
\text { com o mercado; } \\
\text { - Marketing; } \\
\text { - Vendas; } \\
\text { - Positivar Vendas; } \\
\text { - Pós-Vendas. }\end{array}$ & $\begin{array}{l}\text { - Aquisição de } \\
\text { insumos e matéria } \\
\text { prima; } \\
\text { - Armazenagemno } \\
\text { depósito e } \\
\text { almoxarifado; } \\
\text { - Controle de } \\
\text { entregas e estoque. }\end{array}$ & $\begin{array}{l}\text { Programaçãoda } \\
\text { Produção; } \\
\text { Desenvolvimento } \\
\text { de Produtos; } \\
\text { Adequação do } \\
\text { projeto de } \\
\text { Produtos. }\end{array}$ & $\begin{array}{l}\text { - Corte; } \\
\text { - Dobra; } \\
\text { - Furação; } \\
\text { - Solda; } \\
\text { - Lavagem; } \\
\text { - Pintura e Secagem; } \\
\text { - Montagem. }\end{array}$ & $\begin{array}{l}\text { - Corte; } \\
\text { - Usinagem } \\
\text { - Colagem } \\
\text { - Borda; } \\
\text { - Furação; } \\
\text { - Embalagem. }\end{array}$ & $\begin{array}{l}\text { - Armazenamento; } \\
\text { - Separação; } \\
\text { - Carregamento; } \\
\text { - Expedição. }\end{array}$ & $\begin{array}{l}\text { - Conhecimentode } \\
\text { produtos, } \\
\text { materiaise } \\
\text { mercado; } \\
\text { - Relacionamento } \\
\text { estreitocom } \\
\text { clientes; } \\
\text { - Flexibilidade para } \\
\text { adaptação dos } \\
\text { projetos; } \\
\text { - Segurançae } \\
\text { Confiança. }\end{array}$ & \\
\hline
\end{tabular}

Fonte: Dados da pesquisa (2019)

(a) - Usuários finais do produto

(b) - Canais de Distribuição e Representantes

b) Mapeamento das forças competitivas:

No trabalho de mapeamento das forças competitivas, a postura adotada pelo grupo de gestores foi de apontar características gerais das forças competitivas sugeridas na ferramenta de análise proposta por Porter e incorporada ao modelo proposto. Diversos aspectos das Cinco Forças de Porter que exercem influência direta e indireta nos níveis de desempenho da organização foram elencados. No que tange ao poder dos compradores e fornecedores, forças arbitrárias e positivas foram destacadas, em virtude do tipo de relacionamento que a empresa possui no sistema geral do negócio. No Quadro 5 estão sistematizados os resultados da avaliação realizada. 


\begin{tabular}{|c|c|}
\hline \multicolumn{2}{|c|}{ Quadro 5 - Forças Competitivas } \\
\hline : & $\begin{array}{l}\text { Forte competição pelo preço dos produtos; } \\
\text { Poder de marcas mais consolidadas; } \\
\text { Oferta de soluções específicas em mobiliário; } \\
\text { Flexibilidade na oferta de produtos e projetos especiais. } \\
\text { Oferta de produtos de linha média (menor valor agregado); } \\
\text { Design e estética dos produtos; } \\
\text { Diversidade de cores dos produtos; } \\
\text { Rapidez na entrega dos produtos; } \\
\text { Algumas empresas fazem parte de grupo de forte referência no setor moveleiro; } \\
\text { Poder de negociação e agressividade no mercado; } \\
\text { Comportamento e postura nas negociações; }\end{array}$ \\
\hline 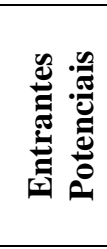 & $\begin{array}{l}\text { Fábricas de móveis já estabelecidas que entram no segmento office e educacional; } \\
\text { Empresas de atuação local que trabalham com alto grau de informalidade; } \\
\text { Empresas criadas por ex-funcionários de indústrias moveleiras, com conhecimentos técnicos; } \\
\text { Novas empresas criadas por empresários com conhecimento do setor; } \\
\text { Novas empresas criadas por grupos de negócio, ligados ou não a indústria moveleira; } \\
\text { Marceneiros que trabalham na informalidade. }\end{array}$ \\
\hline 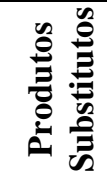 & $\begin{array}{l}\text { Móveis e soluções da linha WorkWalls; } \\
\text { Lojas de peças prontas: vendem peças avulsas de móveis que podem virar mobília para escritório; } \\
\text { Mobiliário multiuso. }\end{array}$ \\
\hline 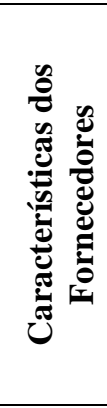 & $\begin{array}{l}\text { Definição do prazo de entrega dos insumos; } \\
\text { Concentração em poucos fornecedores; } \\
\text { Cartelização de preços; } \\
\text { Logística: distância versus custo do transporte; } \\
\text { Fornecimento de insumos de qualidade; } \\
\text { Realizam P\&D para inovação nos insumos fornecidos; } \\
\text { Fornecimento de produtos com certificação de origem; } \\
\text { Preferência por clientes que compram em maior volume; } \\
\text { A empresa possui bom conceito perante seus fornecedores, mesmo sendo de menor porte; } \\
\text { São aproximadamente } 200 \text { fornecedores. No entanto prevalece a proporção de } 25 \% / 75 \% \text {; }\end{array}$ \\
\hline 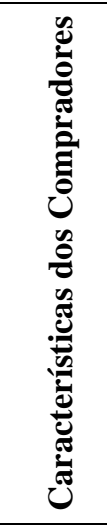 & $\begin{array}{l}\text { Clientes finais: } \\
\text { Pressão por preço baixo. } \\
\text { Clientes Canais: } \\
\text { Pressão pela colocação de showroom; } \\
\text { Possuem clareza sobre a política de preços praticados pela empresa; } \\
\text { São parceiros nas negociações dos valores finais de comercialização; } \\
\text { Trabalham o diferencial das linhas de produtos da empresa no mercado; } \\
\text { Requerem valores diferenciados para venda de produtos de showroom; } \\
\text { Consideram a empresa como fornecedores diferenciado; } \\
\text { Existe muita cautela para incorporação de novos canais; } \\
\text { Todos os canais passam por política de crediário bem rígida. } \\
\text { Recebem comissão em pagamento único, independente do pagamento parcelado da venda. } \\
\text { Não usam o produto da motiva em vendas de baixo valor agregado. }\end{array}$ \\
\hline
\end{tabular}

Fonte: Dados da pesquisa (2019)

\subsection{Desenvolvimento da Fase 2 - Composição dos Indicadores de Desempenho}

O resultado desta fase é a percepção, dentro da Cadeia de Valor e das forças competitivas, dos requisitos necessários para a empresa atingir bons níveis desempenho. O conhecimento destes requisitos permite estabelecer as referências para medir-se com acurácia o grau de desempenho.

a) Identificação dos Requisitos de Desempenho Superior - RDS`́s: 
A identificação dos RDS’s foi realizada em dois momentos e com grupos distintos, num trabalho coordenado de brainstorming e sistematização das informações por meio de adesivos colantes fixados em quadro branco. $\mathrm{O}$ primeiro grupo envolveu os diretores da empresa. $\mathrm{O}$ segundo grupo abrangeu gerentes, coordenadores de setor e colaboradores indicados. As informações foram compiladas para eliminar itens repetidos e agrupar todos os requisitos por afinidade.

No total, 90 RDS's foram apontados. Na tarefa de agrupamento por afinidade, oito dimensões de análise foram estabelecidas, formando o contexto geral para a definição dos Indicadores de Desempenho. A Figura 6 representa as dimensões de análise estabelecidas.

Figura 6-Dimensões de Análise

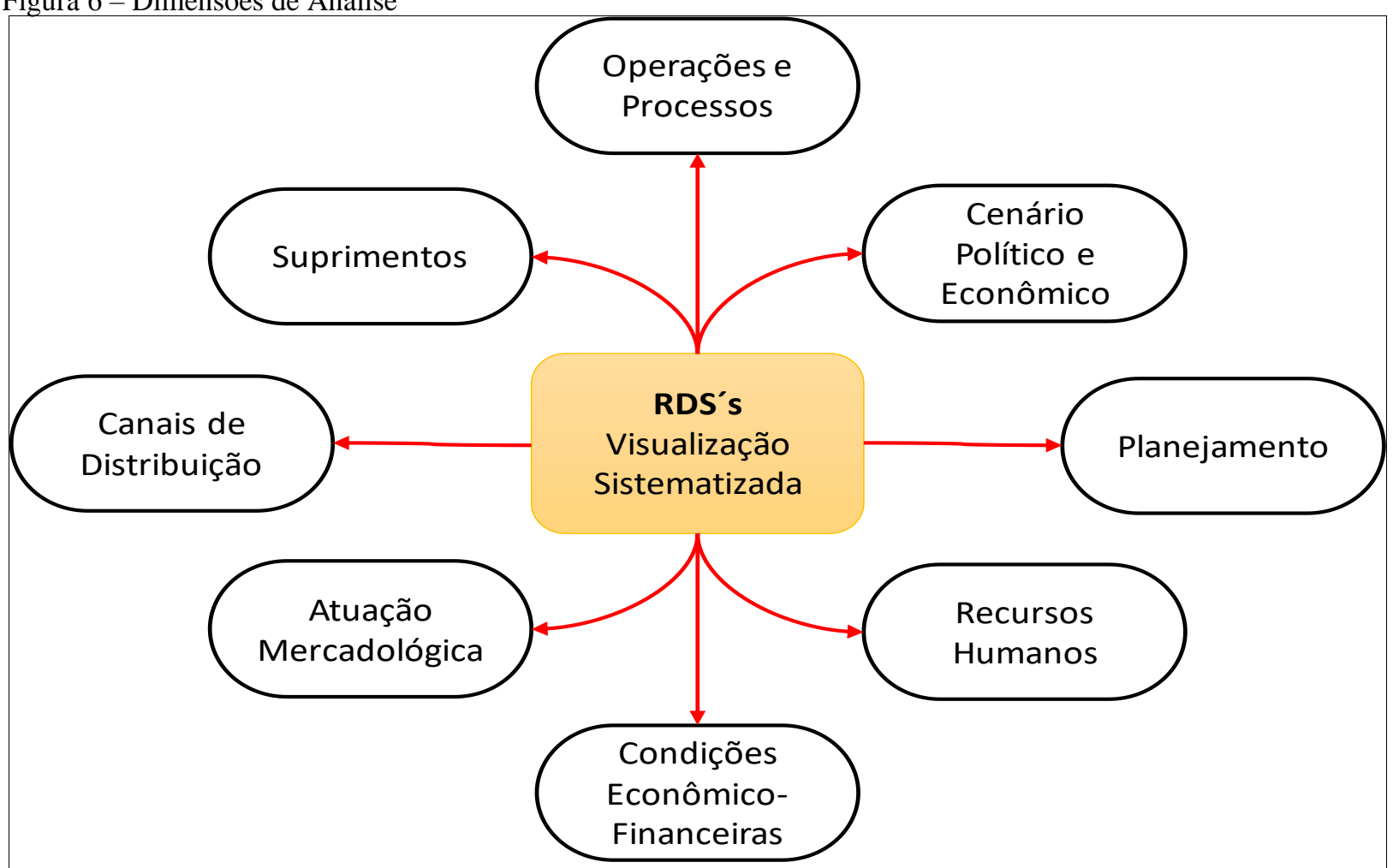

Fonte: Dados da pesquisa (2019)

b) Definição dos Indicadores de Desempenho:

A etapa de definição dos indicadores para avaliação do Grau de Desempenho (GD), centrou as atenções em definir indicadores que permitam a leitura do panorama geral da empresa em relação as suas competências e eficácia diante do cenário competitivo. A base para as definições foram os elementos gerados no desenvolvimento das etapas anteriores. No total, 66 indicadores foram definidos, abrangendo as oito dimensões de análise estipuladas. O Quadro 6 apresenta o grupo de indicadores definidos para cada dimensão de análise.

Quadro 6 - Indicadores de Desempenho 
FAZ CIÊNCIA, VOL. 21, N. 33, JAN/JUN DE 2019 - P. 100-125

\begin{tabular}{|c|c|c|}
\hline Dimensão & \multicolumn{2}{|r|}{ Indicador } \\
\hline \multirow{7}{*}{$\begin{array}{l}\text { Cenário Político e } \\
\text { Econômico }\end{array}$} & CPE1 & Condições Econômicas do país (Brasil) - Produto Interno Bruto (PIB) \\
\hline & CPE2 & $\begin{array}{c}\text { Condições Econômicas do país (Brasil) } \\
\text { ICI - Índice de Confiança da Indústria de Transformação }\end{array}$ \\
\hline & CPE3 & Taxa SELIC \\
\hline & CPE4 & Taxa de Câmbio - Dólar \\
\hline & CPE5 & Taxa de Inflação - IPCA \\
\hline & CPE6 & Situação Política e Econômica do país na perspectiva dos gestores da empresa \\
\hline & CPE7 & $\begin{array}{c}\text { Conjuntura com base nas Informações de entidades representativas da cadeia } \\
\text { moveleira (Abimóvel, Movergs e Sindmóveis) }\end{array}$ \\
\hline & PLN1 & Estrutura do Planejamento Estratégico \\
\hline & PLN2 & Conhecimento do Planejamento Estratégico \\
\hline (2) & PLN3 & Execução do Planejamento Estratégico \\
\hline Planejamento & PLN4 & Estrutura do Planejamento Operacional \\
\hline & PLN5 & Conhecimento do Planejamento Operacional \\
\hline & PLN6 & Execução do Planejamento Operacional \\
\hline & RHU1 & Rotatividade de pessoal (giro de pessoal) \\
\hline & RHU2 & Faltas ao trabalho \\
\hline & RHU3 & Disponibilidade de Recursos Humanos \\
\hline & RHU4 & Remuneração e benefícios pagos aos trabalhadores \\
\hline & RHU5 & Motivação da força de trabalho \\
\hline (3) & RHU6 & Responsabilidade e Comprometimento da força de trabalho \\
\hline Recursos & RHU7 & Confiança e respeito na equipe de trabalho \\
\hline Humanos & RHU8 & Confiança na Direção e Gerência da empresa \\
\hline & RHU9 & Liderança e relacionamento no trabalho \\
\hline & RHU10 & Conhecimento e habilidade para o trabalho \\
\hline & RHU11 & Qualidades das Comunicações \\
\hline & RHU12 & Treinamento e Desenvolvimento adequados da força de trabalho \\
\hline & RHU13 & Existência e cumprimento de procedimentos de trabalho \\
\hline & CEF1 & Faturamento Mensal \\
\hline & CEF2 & Lucro Bruto Mensal \\
\hline (4) & CEF3 & Lucro Líquido Mensal \\
\hline Condição & CEF4 & Liquidez Corrente \\
\hline Econômico- & CEF5 & Capital de Giro \\
\hline Financeira & CEF6 & Margem de Contribuição \\
\hline & CEF7 & Ponto de Equilíbrio \\
\hline & CEF8 & Índice de Endividamento Geral \\
\hline & MER1 & Vendas mensais mercado nacional \\
\hline & MER2 & Vendas mensais mercado internacional \\
\hline & MER3 & Participação de mercado (Setor Moveleiro em Geral) \\
\hline & MER4 & Participação de mercado (Setor Moveleiro Office) \\
\hline Mercadolóoica & MER5 & Índice de Assistência Técnica \\
\hline & MER6 & Condição da Política de preços \\
\hline & MER7 & Credibilidade da marca \\
\hline & MER8 & Estratégias/ações de marketing \\
\hline & CDR1 & Quantidade de Canais de Distribuição - Mercado Nacional \\
\hline & CDR2 & Quantidade de Canais de Distribuição - Mercado Internacional \\
\hline (6) & CDR3 & Quantidade de Representantes \\
\hline Canais de & CDR4 & Grau de Satisfação em relação ao atendimento e serviços prestados \\
\hline Distribuição & CDR5 & Qualidade dos produtos \\
\hline & CDR6 & Solicitações de assistência técnica \\
\hline & CDR7 & Atividades de Treinamento e assistência aos Canais de Distribuição \\
\hline & SUP1 & Quantidade de fornecedores \\
\hline & SUP2 & Relacionamento com Fornecedores \\
\hline $\begin{array}{ll}(/) \\
\text { Sunrimentos }\end{array}$ & SUP3 & Qualidade dos produtos providos pelos fornecedores \\
\hline & SUP4 & Disponibilidades de produtos providos pelos fornecedores \\
\hline & SUP5 & Prazo de entrega dos produtos providos pelos fornecedores \\
\hline$(8)$ & OPR1 & Índice de Produtividade \\
\hline
\end{tabular}




\begin{tabular}{|c|c|c|}
\hline \multirow{4}{*}{$\begin{array}{c}\text { Operações e } \\
\text { Processos }\end{array}$} & OPR2 & Organização e estrutura das instalações da fábrica \\
\cline { 2 - 3 } & OPR3 & Organização e estrutura das instalações administrativas \\
\cline { 2 - 3 } & OPR4 & Existência de Gargalos produtivos \\
\cline { 2 - 3 } & OPR5 & Qualidade do Sistema CRM/ERP \\
\cline { 2 - 3 } & OPR6 & Utilização do Sistema CRM/ERP \\
\cline { 2 - 3 } & OPR7 & Qualidade da Tecnologia de Manufatura \\
\cline { 2 - 3 } & OPR8 & Condições do ambiente de trabalho \\
\cline { 2 - 3 } & OPR9 & Programas de Melhoria contínua dos processos \\
\cline { 2 - 3 } & OPR10 & Manutenção Preventiva das máquinas e equipamentos \\
\cline { 2 - 3 } & OPR11 & Agilidade e flexibilidade das operações e processos \\
\cline { 2 - 3 } & OPR12 & Sistemas de controle das operações e processos \\
\hline
\end{tabular}

Fonte: Dados da pesquisa (2019)

\subsection{Desenvolvimento da Fase 3 - Aferição do Desempenho}

O trabalho de aferição do desempenho reúne esforços em duas frentes estratégicas. No primeiro momento, a fixação das métricas que permitiram a análise do desempenho, a partir da combinação dos elementos quantitativos e cromáticos que o modelo prescreve. No segundo momento, a efetiva aferição do desempenho, via provimento dos resultados para cada indicador de desempenho estabelecido. Na sequência os resultados são descritos.

a) Fixação das Métricas para Análise de Desempenho:

A fixação das métricas para análise de desempenho obedeceu a estrutura da escala de cinco níveis proposta por Rensis Likert, no início dos anos de 1930 (LIKERT, 1932). Todos os 66 indicadores definidos na etapa anterior receberam métricas seguindo o padrão de notas de 1 até 5, com cores representativas da referência de cada nota, conforme exposto no Quadro 7.

Quadro 7 - Padrão para estabelecimento de métricas

\begin{tabular}{|c|c|c|}
\hline Valor & Cor & Referência \\
\hline 5 & & Condições muito boas \\
\hline 4 & & Condições boas \\
\hline 3 & & Condições regulares \\
\hline 2 & & Condições ruins \\
\hline 1 & & Condições muito ruins \\
\hline
\end{tabular}

Fonte: Dados da pesquisa (2019)

As definições levaram em consideração os dados que refletem a trajetória histórica de cada um dos aspectos das diferentes dimensões sob análise. Cabe ressaltar o princípio dinâmico que permeia a fixação das métricas para análise de desempenho. A cada ciclo avaliativo as métricas podem ser modificadas para ajustar-se às situações contextuais e conjunturais, tanto em relação aos recursos, capacidades e competências da organização, quanto dos aspectos externos. 
b) Mensuração do Grau de Desempenho (GD):

A mensuração do GD ocorreu por meio do levantamento de dados em diferentes fontes de informação, tanto internas, quanto externas à organização. No que tange as informações externas, foram coletados dados secundários junto ao Banco Central do Brasil - BACEN, ao Instituto Brasileiro de Geografia e Estatística - IBGE e a Fundação Getúlio Vargas.

Quanto às informações internas, foram tabulados dados secundários dos registros contábeis, registros administrativos e área comercial. Foram aplicados quatro questionários para levantamento de dados primários. Utilizou-se o Questionário 1 para levantamento de informações junto aos diretores e gerentes $(n=5)$; o Questionário 2 para todos os colaboradores ( $n=32)$; o Questionário 3 foi direcionado aos Canais de Distribuição e Representantes (n=14); e o Questionário 4 aos diretores, gerentes e coordenação de áreas $(n=7)$.

A compilação dos dados levantados na etapa de aferição do desempenho foi realizada em planilhas de cálculo específicas por dimensão de análise. A partir dos dados identificados em cada indicador, o desempenho foi estabelecido pela tradução dos resultados segundo a escala definida nas métricas para análise de desempenho.

Seguindo os preceitos do modelo de diagnóstico organizacional utilizado, a visualização e interpretação do desempenho aferido ocorre pela combinação dos elementos visuais que representam as dimensões, os indicadores e as cores relativas para cada grau aferido. Os elementos combinados possibilitam a rápida compressão do quadro global da organização em processo de diagnóstico e de cada indicador em particular. Os resultados desta etapa estão na Figura 7.

\subsection{Desenvolvimento da Fase 4 - Análise de Performance}

A fase final estabelece os Níveis Potencias de Melhoria (NPM), que é a expressão da visão futura dos gestores em relação ao potencial que cada aspecto avaliado possui, e a geração dos Mapas Cromáticos de Análise, ponto nevrálgico do processo de diagnóstico.

a) Estabelecimento dos Níveis Potenciais de Melhoria (NPM’s):

Os NPM’s são grandezas prognosticadas sobre as possibilidades de melhoria que cada aspecto avaliado pelos indicadores de desempenho possui. $\mathrm{Na}$ empresa moveleira sob processo de avaliação, a tarefa de definição dos NPM's correspondentes a cada item foi atribuição dos diretores e gerentes que compunham o grupo de coordenação e desenvolvimento do processo de diagnóstico organizacional. A outorga das notas também seguiu o padrão da escala de Likert e fazem parte da análise exposta na Figura 7. 


\section{FAZ CIÊNCIA, VOL. 21, N. 33, JAN/JUN DE 2019 - P. 100-125}

Figura 7 - Painel de Análise de Desempenho
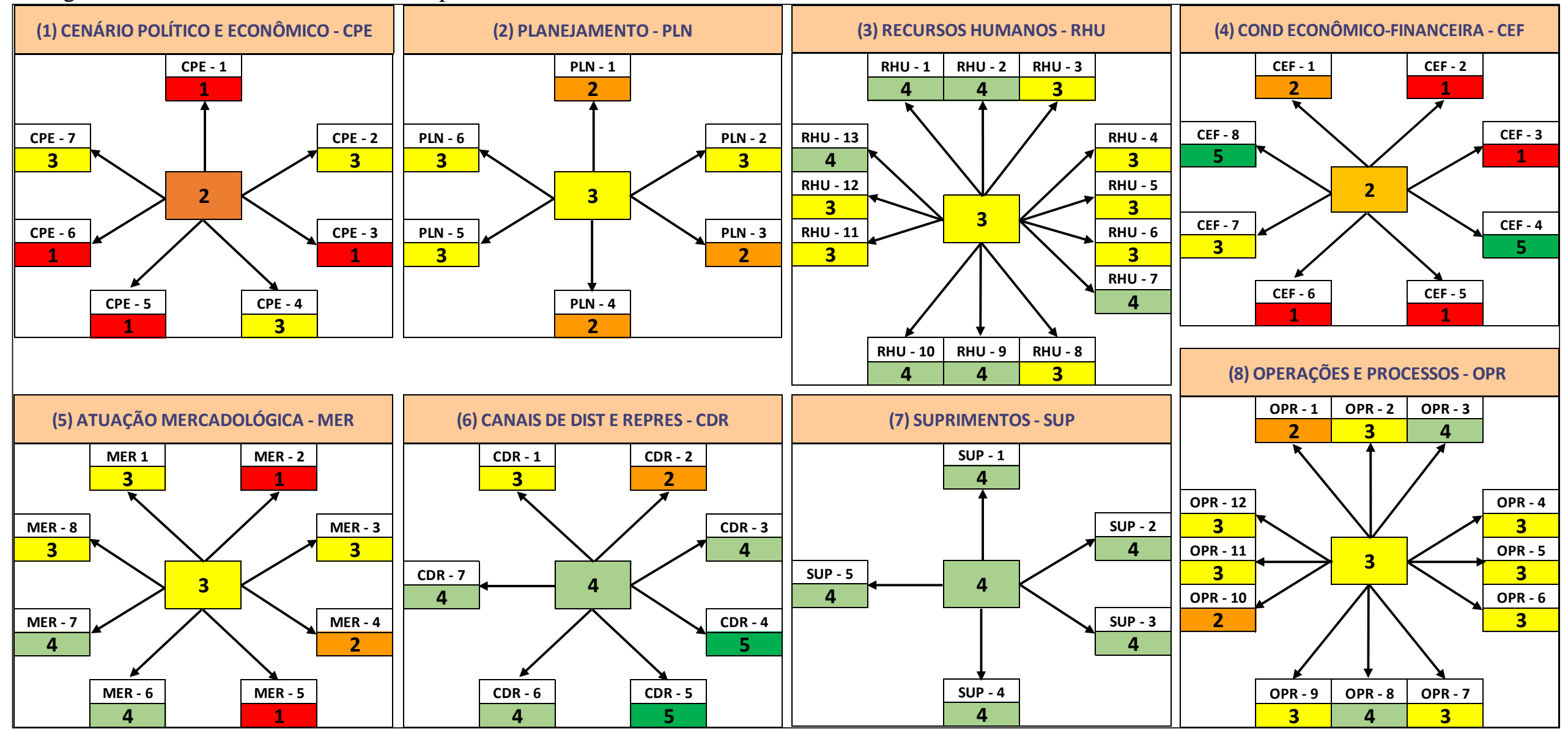

Fonte: Dados da pesquisa (2019) 
b) Geração dos Mapas Cromáticos de Análise (MCA`s):

A etapa final do processo de diagnóstico organizacional é a geração dos Mapas Cromáticos de Análise (MCA). Os MCA's são plotados em gráficos que expressam a relação entre os GD e o NPM de cada indicar definido. Esta associação permite a análise da performance circunstanciada, visto que traduz convergência entre a situação atual e o potencial que cada aspecto avaliado possui. Nos MCA's, a análise da performance é facilitada pela utilização da escala cromática: Verde escuro - Verde claro - Amarelo - Laranja - Vermelho, conforme descrição do Quadro 8.

Quadro 8 - Características por área do MCA

\begin{tabular}{|c|c|}
\hline Área & Características \\
\hline Verde Escuro & Área que representa os pontos mais fortes e que são acompanhados de alto potencial para \\
melhoria no desempenho.
\end{tabular}

Fonte: Dados da pesquisa (2019)

Na Figura 8 são apresentados os MCA`s de cada dimensão do processo de diagnóstico. A verificação do painel de mapas cromáticos aponta características diversas entre os desafios e potencialidades nas oito dimensões de análise. Uma análise ampla aponta as seguintes condições:

a) Dimensão CPE: o GD dos indicadores avaliados situa-se entre as posições média/baixa e o NPM está nos limiares de médio/alto. Mesmo todos os indicadores sendo relacionados a aspectos externos, no médio longo prazo ocorre viés de melhorias;

b) Dimensão PLN: o GD também se situa entre as posições médio/baixo. O NPM de todos os indicadores foi estabelecido em alto, apontando para potencialidades;

c) Dimensão RH: apresenta maior potencialidade. Com exceção de dois indicadores, GD e NPM estão entre médio e alto;

d) Dimensão CEF: prevalecem GD médio/baixo, exceto dois itens que auferiram nota máxima, mas com NPM baixo. O NPM dos demais indicadores ficou entre médio/alto;

e) Dimensão MER: o GD oscila para todas as áreas de análise, prevalecendo a maioria entre médio/baixo. Com exceção de dois indicadores, nos demais o NPM é alto;

f) Dimensão CDR: cinco indicadores possuem GD alto e dois entre médio/baixo. O NPM está no liminar de médio/alto;

g) Dimensão SUP: todos indicadores com GD alto. Todos NPM entre médio/baixo;

h) Dimensão POR: na variação no GD ente toda as zonas de análise. O NPM dos indicadores ficou entre médio/alto, expondo desafios e potencialidades. 
Figura 8 - Painel dos Mapas Cromáticos de Análise

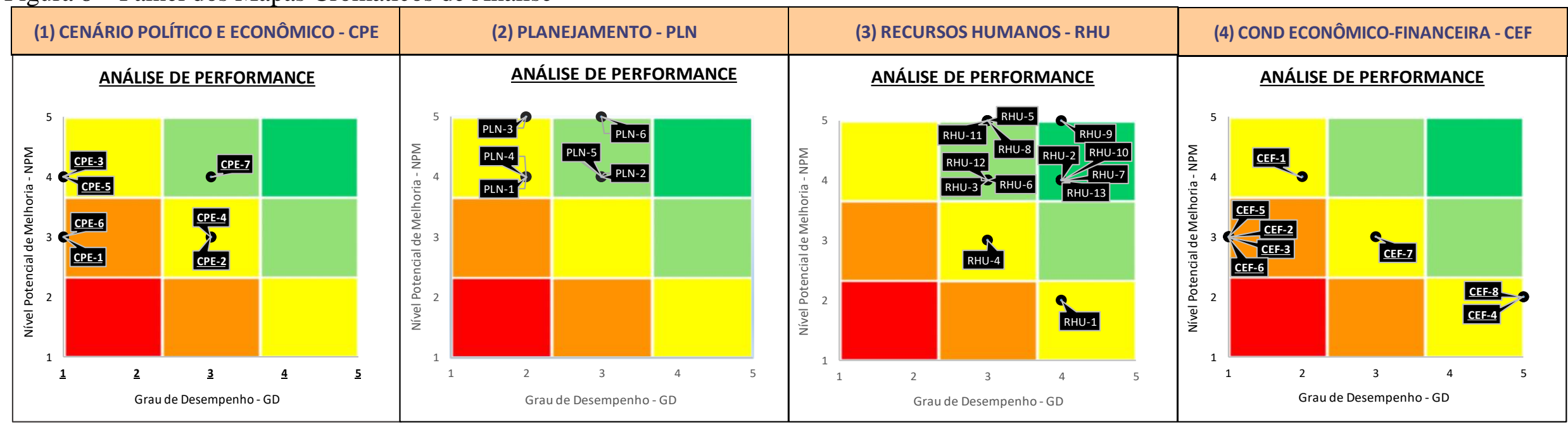

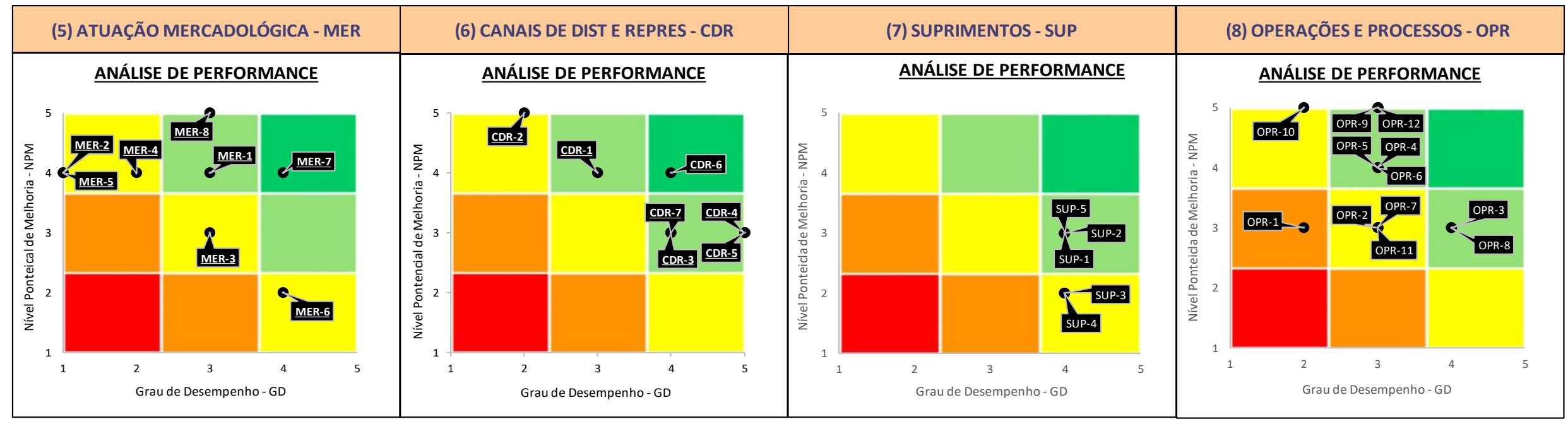

Fonte: Dados da pesquisa (2019) 
Numa visão genérica, o resultado da análise de performance indica que a empresa possui predominância de aspectos positivos, pois mais de 50\% dos itens situam-se nas zonas verde e verde claro, formada por médio/alto GD e NPM. Outros 37\% dos itens encontram-se na zona amarela e um pouco mais de $10 \%$ na área crítica, caracterizada pelas cores vermelho/laranja. Na Tabela 1 esta perspectiva pode ser visualizada.

Tabela 1 - Visualização geral da distribuição dos indicadores

\begin{tabular}{|c|c|c|c|}
\hline Área & Indicadores & N & \% Relativo \\
\hline A / A & RHU-2, RHU-7, RHU-9, RHU-10, RHU-13, MER-7, CDR-6 & 7 & $10,61 \%$ \\
\hline M / A & $\begin{array}{c}\text { CPE-7, PLN-2, PLN-5, PLN-6, RHU-3, RHU-5, RHU-6, RHU-8, RHU-11, } \\
\text { RHU-12, MER-1, MER-8, CDR-1, OPR-4, OPR-5, OPR-6, OPR-9, OPR-12 }\end{array}$ & 18 & $27,27 \%$ \\
\hline A / M & CDR-3, CDR-4, CDR-5, CDR-7, SUP-1, SUP-2, SUP-5, OPR-3, OPR-8 & 9 & $13,64 \%$ \\
\hline B / A & CPE-3, CPE-5, PLN-1, PLN-3, PLN-4, CEF-1, MER-2, MER-4, MER-5, & 11 & $16,66 \%$ \\
\hline M / M & CPE-2, CPE-4, RHU-4, CEF-7, MER-3, OPR-2, OPR-7, OPR-11 & 8 & $12,12 \%$ \\
\hline A / B & RHU-1, CEF-4, CEF-8, MER-6, SUP-3, SUP-4 & 6 & $9,09 \%$ \\
\hline B / M & CPE-1, CPE-6, CEF-2, CEF-3, CEF-5, CEF-6, OPR-1 & 7 & $10,61 \%$ \\
\hline M / M & NENHUM & - & \\
\hline B / B & NENHUM & - & \\
\hline
\end{tabular}

Fonte: Dados da pesquisa (2019)

A análise aprofundada do conjunto de informações geradas pela aplicação do modelo requer o estudo detalhado de cada dimensão e indicador. Entende-se que este trabalho deva ser realizado pelo grupo gestor, pois alimenta o processo de planejamento, a tomada de decisão e a modelagem do negócio da empresa diagnosticada.

$\mathrm{Na}$ avaliação do grupo gestor que coordenou a realização do diagnóstico organizacional, o processo realizado segundo o modelo proposto é consistente e passa confiança na análise dos dados. Isso ocorre em virtude de sua sistemática participativa e metódica de coleta, tabulação e interpretação dos dados e informações referente a estrutura, ao funcionamento e às relações com o ambiente externo. Também, destacam a característica dialética do processo, em razão da promoção de diferentes momentos de pensar e repensar o modelo de negócios da empresa, evidenciando, de forma metódica, as potencialidades que podem ser exploradas e destacando os pontos frágeis que exigem atenção para correção de suas causas.

Fechado o ciclo do processo de diagnóstico, o modelo aplicado entrega aos gestores um conjunto consistente de informações apontadas com rigor e critérios metódicos. Expõe um prognóstico que potencializa um processo consistente de tomada de decisão sobre políticas, estratégias, projetos e ações, com vistas ao desenvolvimento da competitividade das organizações. 


\section{Conclusão}

Um dos grandes desafios enfrentados pelos gestores é tornar e/ou manter suas empresas competitivas no buliçoso contexto em que as organizações atuam. Para tanto, são necessárias capacidades que possibilitem acompanhar o comportamento e as mudanças que afetam a empresa, tanto em seu ambiente interno quanto externo. Conduzir de forma planejada e sistêmica o processo de diagnóstico e análise, é um importante passo na compreensão dos aspectos que interferem nos resultados e força competitiva das organizações.

Neste interim, este estudo foi instigado pela perspectiva sobre quais aperfeiçoamentos no processo de diagnóstico organizacional podem qualificar as informações que subsidiam o processo decisório. À luz desta consideração, o estudo objetivou apresentar os resultados da aplicação prática de um modelo sugerido de diagnóstico organizacional, por meio de estudo de caso realizado em uma organização industrial fabricante de móveis.

Neste viés, a realização deste estudo contribui no desenvolvimento da eficiência operacional e da eficácia mercadológica das organizações. Esta condição ocorre pela proposição de inovações no processo de diagnóstico organizacional, de modo a pragmatizar, qualificar e fortalecer o processo decisório, baseado no fato de a competitividade estar ligada à obtenção, manutenção e uso de recursos apropriados para alcançar-se índices econômicos e técnicooperacionais, valorizados e interpretados como expressões de competência e competitividade.

A realização do diagnóstico na empresa moveleira permitiu o teste prático das ideias consolidadas no modelo proposto. Mesmo diante de limitações em função da dificuldade de reunir-se determinados dados, a dinâmica mostrou-se coesa e os resultados gerados permitiram a sistematização e a avaliação da performance de um conjunto de aspectos que determinam a eficiência e eficácia organizacional, com rigor metodológico.

Outrossim, o estudo realizado corrobora com o avanço científico acerca da temática, na medida em que oferece um modelo estruturado com rigor teórico e procedimentos científicos detalhados. Fornece referências sobre o tema no campo de estudos das Ciências Sociais Aplicadas, contribuindo com a disposição de novos elementos teóricos, principalmente no que tange a incorporação de elementos nas discussões sobre gestão estratégica, mais especificamente voltados ao processo de análise organizacional.

Futuramente, desponta a perspectiva da descrição dos resultados da aplicação prática do modelo em outras organizações. Detalhar a utilização do modelo no contexto de outros setores de referência, como na indústria metalomecânica e em organizações agroindustriais, potencializará a utilização e o refinamento do modelo. Com isso, entende-se que os pressupostos e ferramentas que constituem esta proposta podem ser incorporados a elementos a montante e a 
jusante da fase de diagnóstico, que elevarão o modelo ao patamar de sistema de gerenciamento de performance.

\section{Referenciais Bibliográficos}

BARNEY, J. B.; HESTERLY, W. S. Strategic Management and Competitive Advantage. New Jersey: Prentice Hall, 2010.

BISSELL, B. L.; KEIM, J. Organizational diagnosis: the role of contagion groups. International Journal of Organizational Analysis, vol. 16, n. 1/2, p. 7-17, julho, 2008.

COOPER, D.; SCHINDLER, P. Métodos de Pesquisa em Administração. 12. ed. São Paulo, Bookman, 2016.

GARCIA, L. J. Gestão de Design para melhoramento competitivo de empresa do setor da maricultura: aplicação do modelo CDS com foco em ergonomia. [s.1.] UFSC - Universidade Federal de Santa Catarina, 2013.

GIL, A. C. Como elaborar projetos de pesquisa. São Paulo: Atlas, 2010.

GREGORY, B. T. et al. Achieving scientific rigor in organizational diagnosis: An application of the diagnostic funnel. Consulting Psychology Journal: Practice and Research, vol. 59, n. 2, p. 79-90, 2007.

GUEDES, V. L. S.; BORSCHIVER, S. Bibliometria: uma ferramenta estatística para a gestão da informação e do conhecimento, em sistemas de informação, de comunicação e de avaliação científica e tecnológica. VI CINFORM - Encontro Nacional de Ciência da Informação, 2005.

IEMI, I. DE E. E M. I.; ABIMÓVEL, A. B. DAS I. DO M. Relatório Setorial da Indústria de Móveis no Brasil. São Paulo: [s.n.].

INTERNATIONAL INSTITUTE OF BUSINESS ANALYSIS. A Guide to the Business Analysis Body of Knowledge (BABOK Guide) - Version 2.0. 2. ed. Toronto: International Institute of Business Analysis, 2009.

JUREVICIUS, O. GE McKinsey Matrix. Disponível em: <https://www.strategicmanagementinsight.com/tools/ge-mckinsey-matrix.html>. Acesso em: 7 jul. 2016.

LIKERT, R. A technique for the measurement of attitudes. 22. ed. New York: Archives of Psychology, 1932.

LOK, P.; CRAWFORD, J. The application of a diagnostic model and surveys in organizational development. Journal of Managerial Psychology, vol. 15, n. 2, p. 108-124, março, 2000.

LOVE, T. Philosophy of design: a meta-theoretical structure for design theory. Design Studies, vol. 21, n. 3, p. 293-313, 2000.

MCKINSEY; COMPANY. Enduring Ideas: The GE-McKinsey nine-box matrix. Disponível em: $<$ http://www.mckinsey.com/business-functions/strategy-and-corporate-finance/ourinsights/enduring-ideas-the-ge-and-mckinsey-nine-box-matrix>. Acesso em: 13 jul. 2016.

MERINO, E. A. D.; MERINO, G. S. A. D.; WAGNER, A. Design Management : Application of the Cds Model for Business Diagnostics and the Creation of Competitive Advantage. Internciencia, vol. 42, n. 2, p. 80-87, 2017.

MERINO, G.; GONTIJO, L. A.; MERINO, E. A. D. Modelo CDS Competitividade, Diferenciação e Sustentabilidade Aplicadas ao Design. In: MARTINS, R. F. DE F.; LINDEN, J. C. DE S. VAN DER (Eds.). . Pelos Caminhos do Design. Londrina: EDUEL, 2012. . 
MOUTINHO, L.; RITA, P.; LI, S. Strategic diagnostics and management decision making: a hybrid knowledge-based approach. Intelligent Systems in Accounting, Finance and Management, vol. 14, n. 3, p. 129-155, julho, 2006.

NAG, R.; HAMBRICK, D. C.; CHEN, M.-J. What is strategic management, really? Inductive derivation of a consensus definition of the field. Strategic Management Journal, vol. 28, n. 9, p. 935-955, setembro, 2007.

NAVES, F. L. et al. Diagnóstico organizacional participativo: potenciais e limites na análise de organizações. Organizações \& Sociedade, vol. 7, n. 19, p. 53-66, dezembro, 2000.

NERUR, S. P.; RASHEED, A. A.; NATARAJAN, V. The intellectual structure of the strategic management field: an author co-citation analysis. Strategic Management Journal, vol. 29, n. 3, p. 319-336, março, 2008.

O'CONNOR, J.; MCDERMOTT, I. The Art of Systems Thinking: Essential Skills for Creativity and Problem Solving. London: Thorsons, 1997.

PIAZZA, G. L.; TEIXEIRA, J. M.; MERINO, E. A. D. Diagnóstico para a valorização da produção a partir do modelo CDSII Conferência Internacional de Integração do Design, Engenharia e Gestão para a inovação. Anais...Florianópolis (SC): 2012

PORTER, M. How Competitive Forces Shape Strategy. Harvard Business Review, vol. 57, n. 2, p. $137-145,1979$.

\section{. Competitive Strategy. New York: Free Press, 1980.}

Industrial organization and the evolution of concepts for strategic planning: The new learning. Managerial and Decision Economics, vol. 4, n. 3, p. 172-180, setembro, 1983.

How Information Gives You Competitive Advantage. Harvard Business Review, vol. 63, n. 4, 1985a.

Competitive Advantage: creating and sustaining superior performance. New York: Free Press, $1985 b$.

Towards a Dynamic Theory of Strategy. Strategic Management Journal, vol. 12, p. 95-117, 1991.

The Five Competitive Forces That Shape Strategy. Harvard Business Review, vol. 86, n. 1, p. 78-93, 2008.

PRICE, A. D. F.; NEWSON, E. Strategic Management: Consideration of Paradoxes, Processes, and Associated Concepts as Applied to Construction. Journal of Management in Engineering, vol. 19, n. 4, p. 183-192, outubro, 2003.

PRODANOV, C. C.; FREITAS, E. C. DE. Metodologia do trabalho científico [recurso eletrônico]: métodos e técnicas da pesquisa e do trabalho acadêmico. 2. ed. Novo Hamburgo (RS): Feevale, 2013.

RAMOS-RODRÍGUEZ, A.-R.; RUÍZ-NAVARRO, J. Changes in the intellectual structure of strategic management research: a bibliometric study of the Strategic Management Journal, 1980 2000. Strategic Management Journal, vol. 25, n. 10, p. 981-1004, outubro, 2004.

SACOMANO NETO, M.; TRUZZI, O. M. S. Perspectivas contemporâneas em análise organizacional. Gestão \& Produção, vol. 9, n. 1, p. 32-44, abril, 2002.

SAEED, B. BIN; WANG, W. Organisational diagnoses: a survey of the literature and proposition of a new diagnostic model. International Journal of Information Systems and Change Management, vol. 6, n. 3, p. 222, 2013.

YIN, R. K. Estudo de Caso: Planejamento e Métodos. Porto Alegre: Bookman, 2001. 
WRIGHT, P. L.; KROLL, M. J.; PARNELL, J. A. Strategic Management: concepts. 4. ed. New Jersey: Prentice Hall, 1998.

ZUPIC, I.; CATER, T. Bibliometric methods in management and organization. Organizational Research Methods, vol. 18, n. 3, p. 429-472, 2014.

Recebido em 10/06/2019 - Aprovado em 30/07/2019. 